\title{
Interpretation of drinking water quality guidelines - The case of arsenic
}

\author{
PL Kempster*, M Silberbauer and A Kühn \\ Resource Quality Services, Department of Water Affairs \& Forestry, Private Bag X313, Pretoria 0001, South Africa
}

\begin{abstract}
Drinking water quality guidelines are often interpreted by the non-expert as make or break cut-off values below which drinking water is absolutely safe, and above which it is totally unacceptable. In reality there is no such knifelike cut-off limit, and there is a large grey area between safe water and undrinkable water. The uncertainty of the boundaries of the grey area for each constituent presents a serious problem, both in the creation of sound drinking water quality guidelines or standards, and in the problem of how to interpret the risk to human health when guideline values are exceeded. In this paper this problem is discussed using the case of arsenic, where the definition of the boundaries of the grey area is particularly uncertain.
\end{abstract}

Keywords: drinking water quality, guideline interpretation, arsenic, uncertainties

\section{Introduction}

In order to ensure safe drinking water, and gauge the quality of treated drinking water, guidelines or standards, in terms of concentration of determinands, are customarily defined with which to evaluate the safety of drinking water (SANS, 2005; WHO, 2004). Water service providers are obliged to comply with appropriate water quality standards (DWAF, 2005). The conventional drinking water treatment process of flocculation, sedimentation, filtration and chlorination, is at times hard-pressed to remove trace constituents to levels which satisfy the South African Class 0 (ideal) of the SABS 241:2001 drinking water standard, which in the case of arsenic is set at $10 \mu \mathrm{g} / \ell$ (SABS, 2001). According to the SABS 241:2001 classification system the Class 1 acceptable standard of 10 to $50 \mu \mathrm{g} / \ell$ is also deemed safe for lifetime use. Drinking water authorities are put under great pressure by the public to try and achieve Class 0 (ideal) drinking water quality. Yet the reaching of the stricter level, particularly where the source water contains significant concentrations of arsenic from typically natural causes, presumably due to oxidation of arseno-pyrite, entails careful optimisation of the treatment process and particularly effective filtration to remove fine suspended particulate material. Such careful optimisation of the treatment process has significant cost implications, both in instrumentation needed for monitoring and analysis and costs of treatment chemicals as well as trained operators (DWAF, 2002).

This paper discusses the implications of the uncertainties regarding the relationship between concentrations of the substances in the water and their health effects in interpretation of drinking water quality guidelines. These uncertainties are particularly evident in the case of arsenic.

\section{Health effects of arsenic}

The subject of arsenic in the diet is one which is associated with dread by many, as it is a substance which has been the basis of many historical poisonings, including the death of Napoleon

* To whom all correspondence should be addressed.

욜 +27 21 808-9599; fax: +27 21 808-0338;

e-mail: KempsterP@dwaf.gov.za

Received 16 January 2006
Bonaparte on the island of St. Helena (Weider and Fournier, 1999 ) and the madness of King George III of Britain (Cox et al., 2005). Arsenic is both a toxic substance in excess as well as a carcinogen by inhalation (EPA, 1992). Despite hundreds of studies on arsenic's health effects, the mechanism of action remains uncertain, partly due to the lack of a really suitable animal model, but also because of the contradictory findings in different studies which seem to characterise arsenic epidemiology, and it is still not clear whether arsenic is a primary carcinogen or a cocarcinogen, requiring a carcinogenic partner (Rossman, 2003). Arsenic can give rise to skin cancers, the most obvious with drinking water exposure to elevated arsenic concentrations, as well as to cancers of the lung, bladder and liver (Morales et al., 2000). Ingesting arsenic at concentrations from 300 to 30000 $\mu \mathrm{g} / \ell$ will cause noticeable health effects, and concentrations above $60000 \mu \mathrm{g} / \ell$ can be lethal (ATSDR, 2000).

One of the major challenges in establishing valid doseresponse relationships and especially safe threshold levels for arsenic is that there are not only large interspecies differences, but also genetic variations within humans as to how arsenic is metabolised, which strongly affect susceptibility to the toxic effects of arsenic (Vahter, 1994; Westerfeldt et al., 2001).

To make the understanding even more problematical is the fact that the previously well-accepted hypothesis that toxic inorganic trioxide is detoxified in the body by methylation, has been shown to probably do the reverse, i.e., that the methylation process actually activates arsenic as a toxin and (co)carcinogen (Styblo et al., 2002).

\section{Drinking water guideline limits for arsenic}

The need for sound drinking water guidelines for arsenic is nowhere better illustrated than in the tragedy of the mass chronic arsenic poisoning occurring in Bangladesh and West Bengal where millions of people have been exposed to drinking water containing in excess of $50 \mu \mathrm{g} / \ell$ arsenic and where many show symptoms of chronic arsenic toxicity with both skin and internal organ lesions (Rahman et al., 2001).

It is instructive that the WHO limit for arsenic was originally set at $200 \mu \mathrm{g} / \ell$ in 1958 , based on avoidance of arsenic toxicity, but which was lowered to $50 \mu \mathrm{g} /$ / in 1963 , and still lower 


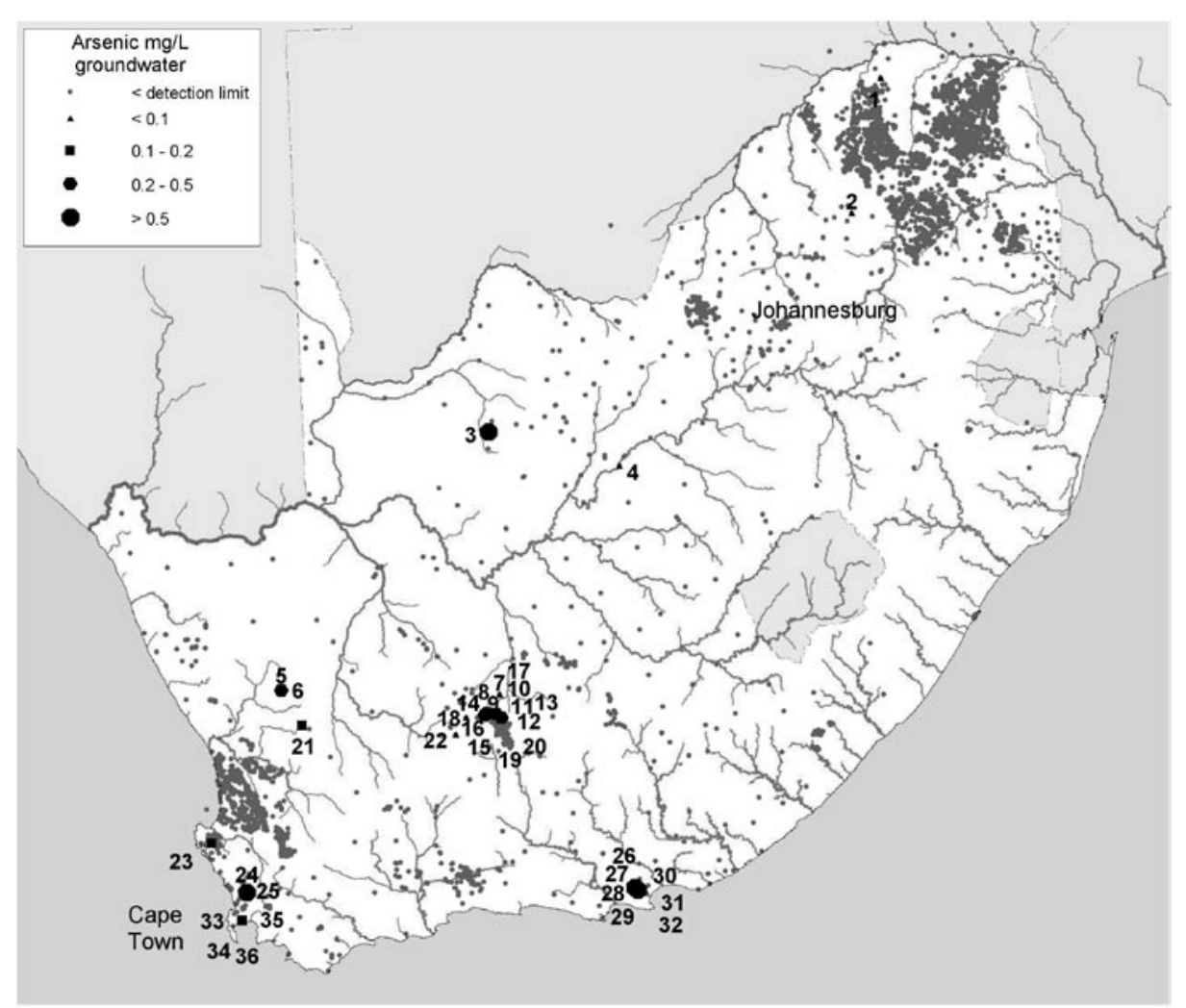

Figure 1

Groundwater arsenic data for South Africa under revision and the indications are that the maximum limit for arsenic will be lowered to 50 $\mu \mathrm{g} / \ell$ (SANS 241, 2005)

\section{Monitoring of arsenic in South African water resources}

There is currently no formal national monitoring programme in place to report on the status of and trends in arsenic levels in South Africa's water resources. Available data are based on a number of surveys that were done by the Department of Water Affairs and Forestry (DWAF) in surface water and groundwater. The data are thus quite patchy, both temporally and spatially. The ability to measure arsenic concentrations at the Class 0 level has also been inconsistent. From 1984 to 1993, the detection limit was $100 \mu \mathrm{g} / \ell$. This improved to $50 \mu \mathrm{g} / \ell$ in 1993 but ageing analytical instruments resulted in a deterioration of the detection limit to $100 \mu \mathrm{g} / \ell$ (in 2000 ), $125 \mu \mathrm{g} / \ell$ (in 2002 to

to the practical analytical quantitation limit of $10 \mu \mathrm{g} / \ell$ in 1993 , which is still regarded as a provisional limit. This lowering of the drinking water guideline for arsenic has been largely due to the fear of an unknown risk of cancer induction, from animal studies which showed arsenic to be a proven carcinogen in animals (WHO, 2004; EPA, 1992). The European Union limit for arsenic in drinking water is also set at the WHO limit of $10 \mu \mathrm{g} / \ell$ (Massey, 2001), while Canada specifies $25 \mu \mathrm{g} / \ell$ (Health Canada, 2004).

There is considerable uncertainty on what the actual risk of cancer in humans is from low levels of arsenic in drinking water. By re-analysing the epidemiological data from the endemic region in Taiwan using several different models, Morales et al. (2000) found the uncertainty of the $1 \%$ excess cancer risk $\left(\mathrm{ED}_{01}\right)$ of lung cancer from arsenic in males to lie between 10 and 364 $\mu \mathrm{g} / \ell$ arsenic in drinking water, and for bladder cancer the $\mathrm{ED}_{01}$ to be in the range of 21 to $633 \mu \mathrm{g} / \ell$. Clearly it is important from the viewpoint of safeguarding human health to set the drinking water guideline limit at the lower limit of the observed range of $1 \%$ excess cancer risk, as other studies have shown that arsenic in combination with other carcinogen-inducing factors such as solar-UV radiation do show effects at lower concentrations of arsenic than isolated arsenic ingestion (Rossman, 2003). Thus the $1958 \mathrm{WHO}$ guideline for arsenic of $200 \mu \mathrm{g} / \ell$ may be protective in the absence of concomitant carcinogens, but the current $10 \mu \mathrm{g} / \ell$ guideline is clearly necessary in view of the fact that humans are exposed to many potential carcinogens in their total diet, apart from solar-UV radiation.

The current South African standard for arsenic in drinking water is set at $10 \mu \mathrm{g} / \ell$ for Class 0 water (ideal), at $50 \mu \mathrm{g} / \ell$ for Class 1 water (acceptable) and at $200 \mu \mathrm{g} / \ell$ for Class 2 water (maximum allowable for a limited period of 3 months) (SABS, 2001). The South African drinking water standard is currently
2004 ) and $200 \mu \mathrm{g} / \ell$ (in 2005). The detection limit would need to be $20 \mu \mathrm{g} /$ lor better for the data to be of use for epidemiological analysis.

A synoptic view of arsenic data for 8380 groundwater samples is shown in Fig. 1. Most groundwater samples had no detectable arsenic (at the detection limits indicated above), and there are only a few sites which showed arsenic values in excess of $200 \mu \mathrm{g} / \ell$ which would be of immediate concern to health (see Table 1 for a complete list of samples that exceeded the detection limit at the time of analysis). The 4 sites that showed toxic levels of arsenic in the red class of $>200 \mu \mathrm{g} / \ell$ were:

- Point 3, a borehole near Sishen: $520 \mu \mathrm{g} / \ell$ As on 1 January 1989

- In the Victoria West area, Point 14, Vingerfontein: $341 \mu \mathrm{g} / \ell \mathrm{As}$ on 12 October 1998 and Point 10, Ruigtefontein: $207 \mu \mathrm{g} / \ell$ As

- Point 29, Site 3325CD00310 G \& I in the Eastern Cape with arsenic in the range 134 to $1664 \mu \mathrm{g} / \ell$ As for 14 samples taken over the period January 1997 to May 2001

- Point 24, Site 3318DA00363 in the Western Cape with 10000 $\mu \mathrm{g} / \ell$ As on 3 November 1999.

A synoptic view of arsenic data for 6360 surface water samples is shown in Fig. 2. This shows that most of the instances of elevated arsenic in surface water have occurred in the industrialised area in and around Gauteng, due presumably to industrial effluent contamination events. Two incidents of note were an arsenic value of $850 \mu \mathrm{g} / \ell$ for the Roodeplaat Canal (Point 42) on $1^{\text {st }}$ December 1989 and an arsenic value of $1233 \mu \mathrm{g} / \ell$ in water from Welbedacht Dam (Point 54) on 5 June 1984. Arsenic is common in arsenopyrite mineralisation in association with iron, so it can dissolve under anaerobic and acidic conditions to create temporary high spikes in observed arsenic concentrations. 


\section{Discussion}

In view of the uncertainty at which real risks to consumers arise from arsenic in drinking water, water treatment authorities need to understand the importance of ensuring that their treated supplies do not contain arsenic above the limits set by the South African Standard (SABS, 2001; SANS, 2005), and that they should aim at ensuring that they meet the standard of $10 \mu \mathrm{g} / \ell$ arsenic in drinking water, with the proviso that: excursions of up to $50 \mu \mathrm{g} / \ell$ are allowed, for a period of up to one year. While skin cancers arising from exposure to arsenic are easily treatable, this is not the case with lung and bladder cancers which lead to much suffering to affected individuals.

Arsenic is not usually present in elevated concentrations in surface waters, unless these have been affected by mining and effluent discharges. Industrial water

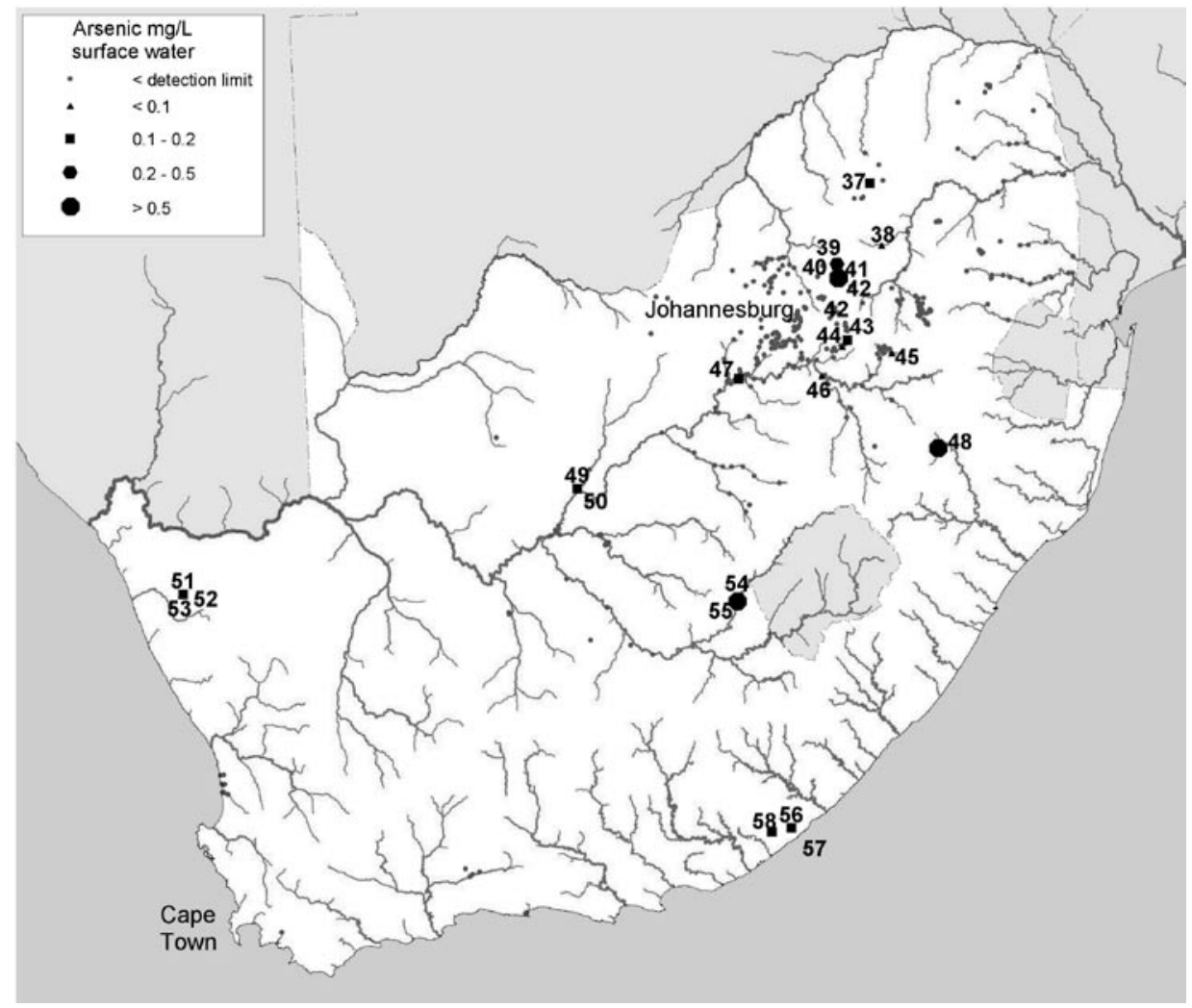

Figure 2

Surface water arsenic data for South Africa

use and wastewater discharges are regulated in terms of the National Water Act (Act No 36 of 1998) and point sources of pollution are well under control. The real risk of arsenic presence in water lies with groundwater supplies, particularly in areas where arsenic-containing minerals are found. It has been a standing policy within our Department of Water Affairs and Forestry that all new boreholes intended for use for drinking water should be tested for acceptability for use, particularly with respect to the arsenic, nitrate and fluoride concentrations in addition to the usual total dissolved salts (DWAF, 1998).

A worrying feature of risk information published on arsenic is that the risk is determined for a very specific scenario and using a very specific epidemiological model. The assumptions used in the derivation of the risk figure are often forgotten and the numerical risk itself is thereafter taken as absolute truth. In the exhaustive review of arsenic carcinogenesis by Rossman (2003) many cases occurred where the threshold for observation of carcinogenesis in animals was strongly influenced by many factors, including genetic and dietary factors, as well as the exposure to co-carcinogens and vitamins. This implies that the risk factors cannot be used as generalisations. For instance, despite the hundreds of articles on observed arsenic carcinogenesis in animals, it is still not certain that arsenic is a primary carcinogen in humans (Rossman, 2003). Yet the modelled risk level for arsenic- induced cancer at $10 \mu \mathrm{g} / \ell$ has been quoted as being as high as 1 in 1700 (Massey 2001) or 1 in 500 at $50 \mu \mathrm{g} / \ell$ (Morales et al., 2000). The uncertainties of risk assessment epidemiological models imply, if they are taken at face value, that arsenic in drinking water may be a leading cause of cancer in humans, as the safety factors for organic carcinogens such as pesticides are normally managed at the 1 in 1000000 risk level (Massey, 2001).

It is frustrating to say that neither the level at which arsenic carcinogenesis kicks in nor the mechanism of action is clearly understood (Rossman, 2003; Morales et al., 2000), nor the reasons for why a small percentage of individuals are particularly susceptible to the toxic effects of arsenic (Westerveldt Check spelling et al., 2001). Ideally epidemiological studies should be conducted to establish the applicability of available risk assessment models to the South African situation.

Despite these fears, arsenic does have potentially positive benefits in the medical and nutritional fields, and there is already strong evidence that arsenic may be essential in small quantities in certain animal species. It is, however, not yet known in what form the arsenic is best taken, nor what the exact beneficial amount is (Nielsen, 1998; Munshi et al., 2002). Tarello (2001a) has shown that chronic fatigue syndrome in cats can be rapidly brought into complete remission using treatment with small doses of arsenic. This syndrome, with elements of immune suppression resembling HIV disease in humans, can be effectively brought into remission in birds (Tarello, 2001b), and in dogs as well (Tarello, 2001c) using small-dose arsenic treatment. Arsenic has been used in human medicine for centuries especially for treating parasitic infections (Munshi et al., 2002). In relation to the human HIV/AIDS pandemic, Fincham et al. (2003) and Adams et al. (2005) have postulated that soil-transmitted helminthic infection could be a significant risk factor. The intriguing possibility thus exists that dietary arsenic intake in food and water may be a negative risk factor in the HIV infection. However, the form in which the arsenic is present is probably critical due to the large differences in metabolic pathways of different arsenic species (Styblo et al., 2002). Toxicologists believe that inorganic arsenic is mainly responsible for cancer whereas arsenobetaine or 'fish arsenic' is considered relatively non-toxic (Ryan et al., 2001). A typical Japanese fish-rich diet contributes as much as $195 \mu \mathrm{g} / \mathrm{d}$ arsenic (Yamauchi et al., 1992), whereas an American diet only contributes around $28 \mu \mathrm{g} / \mathrm{d}$ (Ryan et al., 2001). 


\begin{tabular}{|c|c|c|c|c|}
\hline \multicolumn{5}{|c|}{$\begin{array}{c}\text { TABLE } 1 \\
\text { Raw data for all monitoring points where arsenic exceeded the current detection limit }\end{array}$} \\
\hline Point & Description on DWAF database & & Date & As $(\mu \mathrm{q} / \ell)$ \\
\hline 1 & ZQMALL2 2229AC00129 Alldays & (borehole) & 1999-04-19 & 82 \\
\hline 2 & ZQMNAB4 2428DA00613 Groot Valley - Naboomspruit & (borehole) & 1999-04-26 & 80 \\
\hline \multirow[t]{2}{*}{3} & \multirow[t]{2}{*}{ ZQM783HAL Borehole on Halliford near Sishen D4N783Q01 } & \multirow[t]{2}{*}{ (borehole) } & $1985-08-05$ & 126 \\
\hline & & & $1989-06-01$ & 520 \\
\hline 4 & Abramsyskraal & (borehole) & $2000-02-07$ & 93 \\
\hline \multirow[t]{4}{*}{5} & \multirow{4}{*}{ 3019CD00056 Loeriesfontein Meent } & \multirow[t]{4}{*}{ (borehole) } & $2000-03-17$ & 136 \\
\hline & & & $2000-03-17$ & 155 \\
\hline & & & $2000-03-18$ & 209 \\
\hline & & & $2000-03-20$ & 149 \\
\hline 6 & 3019CD00057 Loeriesfontein Meent & (borehole) & $2000-03-25$ & 162 \\
\hline \multirow[t]{2}{*}{7} & 3123AC00226 Victoria West Allotment & (borehole) & $2000-03-29$ & 74 \\
\hline & & & $2000-03-29$ & 64 \\
\hline 8 & Vingerfontein 162 & (borehole) & $1999-02-09$ & 61 \\
\hline & & & $1999-02-11$ & 72 \\
\hline 9 & Vingerfontein 162 & (borehole) & 1999-02-03 & 100 \\
\hline & & & 1999-02-05 & 280 \\
\hline 10 & \begin{tabular}{|l|} 
Ruigtefontein 169 \\
\end{tabular} & (borehole) & $1999-06-11$ & 207 \\
\hline 11 & Ruigtefontein 169 & (borehole) & $1999-07-23$ & 202 \\
\hline 12 & 3123AC00208 Ruigtefontein & (borehole) & 1999-12-04 & 87 \\
\hline & & & $1999-12-05$ & 76 \\
\hline & & & $1999-12-08$ & 90 \\
\hline 13 & Ruigtefontein 169 & (borehole) & 1999-07-21 & 189 \\
\hline 14 & Vingerfontein & (borehole) & $1998-10-10$ & 78 \\
\hline & & & $1998-10-12$ & 222 \\
\hline & & & $1998-10-12$ & 341 \\
\hline 15 & Vingerfontein & (borehole) & $1998-09-30$ & 117 \\
\hline & & & 1998-10-09 & 239 \\
\hline 16 & Vingerfontein & (borehole) & $1998-10-13$ & 154 \\
\hline 17 & 3122BD00111 Vingerfontein & (borehole) & $1999-11-25$ & 66 \\
\hline 18 & Taaiboschfontein & (borehole) & $1998-08-19$ & 65 \\
\hline 19 & Victoria West Allotment & (borehole) & 1999-04-26 & 150 \\
\hline & & & $1999-04-27$ & 241 \\
\hline 20 & Victoria West Allotment & (borehole) & $1999-06-14$ & 110 \\
\hline 21 & ZQMCLV1 3119BD00036 Calvinia Allotment - CT59 & (borehole) & $1999-05-03$ & 140 \\
\hline 22 & Duikerfontein & (borehole) & $1999-10-16$ & 62 \\
\hline 23 & 3218CC00387 Langeberg G46063 & (borehole) & $2001-05-04$ & 116 \\
\hline$\frac{24}{24}$ & ZQC000051 3318DA00363 Vryheid - 51/1B & (borehole) & $1999-11-03$ & 10000 \\
\hline 25 & 3318DA00118 Mikpunt 181/1B & (borehole) & $2002-02-12$ & 59 \\
\hline 26 & G \& I & (borehole) & $1996-10-21$ & 267 \\
\hline 27 & Kruisrivier: G \& I & (borehole) & $1995-09-27$ & 363 \\
\hline & & & \begin{tabular}{|l|}
$1996-04-24$ \\
\end{tabular} & 234 \\
\hline 28 & Kruisrivier: G \& I & (borehole) & 1999-09-09 & 400 \\
\hline 29 & 3325CD00310 ZQCSKR3 G \& I - G40036 & (borehole) & $1997-01-28$ & 1664 \\
\hline & & & 1997-04-24 & 1439 \\
\hline & & & $1997-07-23$ & 600 \\
\hline & & & $1997-10-29$ & 1133 \\
\hline & & & $1998-03-05$ & 134 \\
\hline & & & 1998-09-02 & 280 \\
\hline & & & $1998-12-07$ & 543 \\
\hline & & & $1999-03-04$ & 441 \\
\hline & & & $1999-12-02$ & 597 \\
\hline & & & $2000-03-25$ & 699 \\
\hline & & & $2000-07-10$ & 1182 \\
\hline & & & $2000-10-10$ & 1200 \\
\hline & & & $2001-01-05$ & 1094 \\
\hline & & & $2001-05-01$ & 646 \\
\hline 30 & $\mathrm{CGH}$ & (borehole) & $1996-08-23$ & 469 \\
\hline & & & $1996-10-23$ & 444 \\
\hline 31 & 3325CD00315 ZQCSKR9 C G H Ponds - G40042 & (borehole) & $1997-10-28$ & 1269 \\
\hline & & & 1998-03-04 & 188 \\
\hline & & & $1998-09-03$ & 347 \\
\hline & & & $1998-12-07$ & 226 \\
\hline & & & 1999-03-04 & 307 \\
\hline & & & $1999-09-10$ & 252 \\
\hline & & & $1999-12-01$ & 353 \\
\hline & & & $2000-03-24$ & 274 \\
\hline & & & $2000-07-11$ & 244 \\
\hline & & & $2000-10-10$ & 379 \\
\hline & & & \begin{tabular}{|l|l|l|l|}
$2001-01-05$ \\
\end{tabular} & 424 \\
\hline 32 & 3325CD00313 ZQCSKR8 Uitenhage Sewage Works - G40041 & (borehole) & $1995-09-28$ & 212 \\
\hline & & & $1995-11-21$ & 272 \\
\hline & & & $1996-04-24$ & 262 \\
\hline 33 & ZQM196MPL 3418BA00001 Mitchell's Plain - G32963 G2N196Q01 & (borehole) & $1986-03-13$ & 121 \\
\hline 34 & ZQM199MPL 3418BA00018 Mitchell's Plain - G 32966 G2N199Q01 & (borehole) & $1986-03-13$ & 114 \\
\hline$\frac{34}{35}$ & ZQM200MPL 3418BA00037 Mitchell's Plain - G 32967 G2N200Q01 & (borehole) & $1986-03-13$ & 139 \\
\hline
\end{tabular}




\begin{tabular}{|c|c|c|c|c|}
\hline 36 & ZQM198MPL 3418BA00020 Mitchell's Plain - G032965 G2N198Q01 & (borehole) & $1986-03-13$ & 139 \\
\hline 37 & A6H025R01 Makopane: Doorndraai Dam raw water & (WPW) & $1989-12-06$ & 150 \\
\hline 38 & B3H010R02 South Ndebele: Renosterkop Dam raw water & (WPW) & 1993-03-01 & 57 \\
\hline 39 & A2H070R01 Klipdrift: Roodeplaat Dam raw water & (WPW) & 1990-04-03 & 404 \\
\hline \multirow[t]{2}{*}{40} & \multirow[t]{2}{*}{ A2H070S01 Klipdrift: potable water } & \multirow[t]{2}{*}{ (WPW) } & $1984-12-05$ & 105 \\
\hline & & & $1990-04-03$ & 177 \\
\hline \multirow[t]{4}{*}{41} & \multirow[t]{4}{*}{ A2H071S01 Wallmannsthal potable water } & \multirow[t]{4}{*}{$($ WPW) } & $1989-11-01$ & 950 \\
\hline & & & $1989-12-01$ & 780 \\
\hline & & & $1990-02-28$ & 271 \\
\hline & & & $1990-04-03$ & 526 \\
\hline \multirow[t]{2}{*}{42} & \multirow[t]{2}{*}{ A2H071R01 Wallmannsthal: Roodeplaat Dam raw water } & \multirow[t]{2}{*}{ (WPW) } & $1989-12-01$ & 850 \\
\hline & & & 1990-02-28 & 653 \\
\hline 43 & C2H183Q01 R42 Delmas-Nigel road bridge & (river) & $1999-02-15$ & 160 \\
\hline 44 & C2H185Q01 Poortjie Road on Blesbokspruit & (river) & 1994-08-02 & 50 \\
\hline 45 & C1H033Q01 RESM 8 Klipspruit upstream Secunda & (river) & $1995-08-23$ & 50 \\
\hline 46 & C1H013R01 Vaal Dam raw water & (WPW) & 1993-02-01 & 53 \\
\hline 47 & ZKOEK-BUF Koekemoer Spruit at Buffelsfontein & (river) & $1994-11-07$ & 171 \\
\hline 48 & V3H021R01 Ngagane Treatment Works - Chelmsford Dam raw water & (WPW) & 1984-07-03 & 820 \\
\hline 49 & C9H012R01 Vaal Gamagara Treatment Works - Vaal River raw water & (WPW) & $1984-02-02$ & 120 \\
\hline 50 & C9H012S01 Vaal Gamagara Treatment Works - treated water & (WPW) & 1984-06-02 & 115 \\
\hline \multirow[t]{2}{*}{51} & \multirow[t]{2}{*}{6 Springbok Municipal Area SHC sump } & \multirow[t]{2}{*}{ (river) } & $2002-07-29$ & 200 \\
\hline & & & $2002-10-02$ & 100 \\
\hline 52 & 7 Springbok Municipal Area downstream of N7 & (river) & $2002-10-02$ & 80 \\
\hline 53 & 1 Springbok Municipal Area commonage boundary & (river) & $1997-03-18$ & 25 \\
\hline \multirow[t]{2}{*}{54} & \multirow[t]{2}{*}{ D2H021R01 Caledon / Bloemfontein: Welbedacht Dam raw water } & (WPW) & 1984-06-05 & 1233 \\
\hline & & & $1993-01-04$ & 56 \\
\hline \multirow[t]{2}{*}{55} & \multirow[t]{2}{*}{ D2H021S01 Caledon / Bloemfontein: treated water } & \multirow[t]{2}{*}{$(\mathrm{WPW})$} & $1984-01-10$ & 427 \\
\hline & & & $1984-12-03$ & 101 \\
\hline 56 & R3H002R01Nahoon Dam raw water & (WPW) & 1984-11-05 & 113 \\
\hline \multirow[t]{2}{*}{57} & \multirow[t]{2}{*}{ R3H002S01Nahoon Dam treated water } & \multirow[t]{2}{*}{ (WPW) } & $1984-11-05$ & 111 \\
\hline & & & $1984-12-03$ & 106 \\
\hline 58 & R2H014S01 Middle Buffalo: treated water & (WPW) & $1986-02-03$ & 107 \\
\hline
\end{tabular}

If it is assumed, for the sake of argument, that the Japanese diet, high in fish intake, represents the dietary picture for early man who lived close to the sea, then on the basis of the safe drinking water arsenic intake being $10 \%$ of the total dietary intake, the safe arsenic drinking water limit would be around $10 \mu \mathrm{g} / \ell$ As for a $2 \ell$ per day water intake for an adult, and 195 $\mu \mathrm{g} / \mathrm{d}$ As from food intake (Yamauchi et al., 1992). Now this is exactly at the current WHO (2004) guideline for arsenic, which probably is confirmation that it is a reasonable limit in terms of safety with respect to the total diet. However, should the diet be deficient in fish intake, then $10 \mu \mathrm{g} / \ell$. As may well be a deficiency level for arsenic and below the level of optimal benefit to human health and well-being, and the Canadian limit of $25 \mu \mathrm{g} / \ell$ may be more appropriate.

Knowing the typical food basket total dietary intake of arsenic is important in reaching balanced decisions on what the drinking water standard or guideline for a naturally occurring constituent should be. Unfortunately the role of naturally occurring arsenic in fish and water in human diets and health is not known, but evidence from animal and human studies shows that it may play a significant health role in small concentrations (Nielsen, 2000). There is an unfortunate trend in drinking water guidelines for naturally occurring substances to be reduced as the years pass, on the grounds of carcinogenicity at unrealistically high doses in animal experiments. Standard linear extrapolation models for calculating cancer risks at low dose exposure to carcinogens almost certainly seriously overestimate risk, as about half of chemicals tested for carcinogenicity in rodents give a positive response at high dose levels, and the response at low dose is fundamentally different (Ames and Gold, 1997). Where water is the vehicle for an essential trace element, excessively low drinking water guidelines based on linear extrapolation risk assessment models may well do the consumer a disservice, as well as raising untested and alarmist fears.

In view of the growing incidence of HIV infection in humans, as well as associated syndromes where immune dysfunction plays a role, such as chronic fatigue syndrome in humans and animals, it is important for water suppliers not to induce trace mineral deficiencies through drinking water that is too pure and devoid of minerals. This is particularly a risk from the modern popularity of point-of-use reverse osmosis units, which reduce the mineral content of water and particularly trace elements to very low levels. The ideal level of intake of naturally occurring mineral elements may be in a small window of concentration between deficiency and toxicity. For example, the element selenium, adjacent to arsenic on the periodic table, is toxic at $\mathrm{mg} / \ell$ concentrations, but is required in the diet in small amounts (about $20 \mu \mathrm{g} / \ell$ : Oldfield, 1987).

\section{Conclusion}

This paper has shown the importance of interpreting drinking water guidelines on a very broad front, and the importance of not only looking at high-dose risk extrapolation data in evaluating what the safe dose is for naturally occurring elements in the total diet. There is a great danger that risk of cancer may force increasing pressure for standards bodies to reduce the drinking water limits of naturally occurring elements still further, and with the technology available to achieve chemically clean water, there is a real risk of inducing deficiency diseases in the population. This may already be happening with arsenic, for which there is growing evidence of a role in the immune system. The risk is real, as conventional water treatment already automatically removes arsenic by complexation to iron or aluminium flocculants, thus providing a water which is guaranteed almost free of arsenic. While erring on the side of caution in cancer prevention, we may quite unknowingly encourage the appearance of chronic deficiency diseases where the diet is limited. It is thus vitally important to maintain a balanced view of what constitutes a safe water and to promote the importance of proper nutri- 
tion in the total diet, both from the viewpoint of food as well as from water. Ideally arsenic and other potentially harmful substances should be monitored on a long-term basis so that these data can be linked to epidemiological studies to make water quality guidelines more appropriate to South African conditions in order to ensure that the health of the South African population is protected optimally on a more site-specific basis.

\section{Acknowledgments}

This information is published with the kind permission of the Department of Water Affairs and Forestry, South Africa. The contents of the paper are personal views of the authors and do not necessarily reflect the position of the Department of Water Affairs and Forestry.

\section{References}

ADAMS VJ, MARKUS MB, ADAMS JFA, JORDAAN E, CURTIS B, DHANSAY MA, OBIHARA CC and FINCHAM JE (2005) Paradoxical helminthiasis \& giardiasis in Cape Town, South Africa: Epidemiology \& control. Afr. Health Sci. 5 (2) 131-136.

AMES BN and GOLD LS (1997) The causes \& prevention of cancer: Gaining perspective. Environ. Health Perspect. 105 (4) 6

ATSDR (2000) Agency for toxic substances and disease registry: Public Health Statement for Arsenic. Online at http://www.atsdr.cdc.gov toxprofiles/phs2.htm (Accessed in November 2005).

COX TM, JACK N, LOFTHOUSE S, WATLING J, HAINES J and WARREN MJ (2005) King George III and porphyria: an elemental hypothesis and investigation. Lancet 366 (9482) 332-335.

DWAF (1998) Quality of Domestic Water Supplies Vol. 1: Assessment Guide. WRC Report No TT 101/98. Dept. of Water Affairs \& Forestry, Dept of Health and the Water Research Commission (WRC). $104 \mathrm{pp}$.

DWAF (2002) Quality of Domestic Water Supplies Vol. 4: Treatment Guide. WRC Report No TT 181/02. Dept. of Water Affairs \& Forestry, Dept of Health and the Water Research Commission (WRC). $85 \mathrm{pp}$.

DWAF (2005) South African Compulsory National Standards for the Quality of Potable Water. Department of Water Affairs \& Forestry, Pretoria, as required by the Water Services Act no 108 of 1997.

EPA (1992) Arsenic Compounds-Hazard Summary. US Environmental Protection Agency. Online at http://www.epa.gov/ttn/atw/hlthef arsenic.htm (Accessed in November 2005).

FINCHAM JE, MARKUS MB and ADAMS VJ (2003) Could control of soil-transmitted helminthic infection influence the HIV/AIDS pandemic? Acta Tropica 86 315-333.

HEALTH CANADA (2004) Summary of Guidelines for Canadian Drinking Water Quality. Territorial Committee on Health \& the Environment. Online at www.hc-sc.gc.ca/waterquality (Accessed in November 2005). 1-11.

MASSEY R (2001) Arsenic from your tap, from Rahel's Environment \& Health News. Online at www.njpcgreens.org/arsenic.htm (Accessed in November 2005). 5.

MORALES KH, RYAN L, KUO T-L, WU M-M and CHEN C-J (2000)
Risk of internal cancers from arsenic in drinking water. Environ Health Perspect. 108 (7) 655-661.

MUNSHI NC, TRICOT G, DESIKAN R, BADROS A, ZANGARI M, TOOR A, MORRIS C, ANAISSIE E and BARLOGIE B (2002) Clinical activity of arsenic trioxide for the treatment of multiple myeloma. Leukemia 16 1835-1837.

NIELSEN FH (2000) Importance of making dietary recommendations for elements designated as nutritionally beneficial, pharmacologically beneficial, or conditionally essential. J. Trace Elements Exp. Med. 13 (1) 113-129.

OLDFIELD JE (1987) The two faces of selenium. J Nutr. 117 (12) 20022008.

RAHMAN MM, CHOWDHURY UK, MUKHERJEE SC, MONDAL BK, PAUL K, LODH D, BISWAS BK, CHANDA CR, BASU GK, SAHA KC, ROY S, DAS R, PALIT SK, QUAMRAZZAMAN Q and CHAKRABORTI D (2001) Chronic arsenic toxicity in Bangladesh \& West Bengal, India - A review \& commentary. Clin. Toxicol. 39 (7) $683-700$.

ROSSMAN TG (2003) Mechanism of arsenic carcinogenesis: an integrated approach. Mutation Res. 553 37-65.

RYAN PB, SCANLON KA and MACKINTOSH DL (2001) Analysis of dietary intake of selected metals in the NHEXAS-Maryland investigation. Environ. Health Perspect. 109 (2) 121-128.

SABS (2001) South African Standard Specification 241: Drinking Water (edn.5). South African Bureau of Standards Gr7, ISBN 0-62612908-7, Pretoria. 9 pp.

SANS (2005) South African National Standard 241: Drinking Water (edn. 6). South Africa, Pretoria.

STYBLO M, DROBNA Z, JASPERS I, LIN S and THOMAS DJ (2002) The role of biomethylation in toxicity and carcinogenicity of arsenic: A research update. Environ. Health Perspect. 110 (5) 767-771.

TARELLO W (2001a) Chronic fatigue syndrome (CFS) in cats: Symptoms, diagnosis \& treatment of 7 cases. Revue de Médecine Vétérinaire. 152 (11) 1-13.

TARELLO W (2001b) Chronic fatigue \& immune dysfunction syndrome associated with Staphylococcus spp. Bacteraemia responsive to Thiacetarsamide sodium in eight birds of prey. J. Vet. Med. 48 (4) 267.

TARELLO W (2001c) Chronic fatigue syndrome (CFS) associated with Staphylococcus spp. Bacteraemia, responsive to thiacetarsamide sodium in 7 dogs. Revue de Médecine Vétérinaire. 152 (11) 8.

VAHTER M (1994) Species differences in the metabolism of arsenic compounds. Appl. Organomet. Chem. 8 (3) 175-182.

WEIDER B and FOURNIER JH (1999) Activation analysis of authenticated hairs of Napoleon Bonaparte confirm arsenic poisoning. Am. J. For. Med. Path. 20 (4) 378-382.

WESTERVELDT P, BROWN RA, ADKINS DR, KHOURY H, CURTIN P, HURD D, LUGER SM, MA MK, LEY TM and DiPERSIO JF (2001) Sudden death among patients with acute promyelocytic leukaemia treated with arsenic trioxide. Blood 98 (2) 266-271.

WHO (WORLD HEALTH ORGANISATION) (2004) Guidelines for Drinking-Water Quality ( $3^{\text {rd }}$ edn.) Vol 1 Recommendations. WHO, Geneva. 515 pp.

YAMAUCHI $\mathrm{H}$, TAKAHASHI $\mathrm{K}$, MASHIKO $\mathrm{M}$, SAITOH $\mathrm{J}$ and YAMAMURA Y (1992) Intake of different chemical species of dietary arsenic by the Japanese, and their blood and urinary levels. Appl. Organomet. Chem. 6 (4) 383-388. 